\title{
Effect of Heat Treatments on Fatigue Properties of Ti-6Al- 4V Alloy Fabricated by EBM Additive Manufacturing
}

\author{
Dong-Geun Lee ${ }^{*}$, Youngsin Choi ${ }^{2,3}$ \\ ${ }^{1}$ Sunchon National University, 255, Jungang-ro, Suncheon-Si, 57922, Republic of Korea \\ 2 Department of Materials Engineering, Hanyang University, Ansan, 15588, Republic of Korea \\ ${ }^{3}$ Incheon Regional Division, Korea Institute of Industrial technology, Incheon, 21999, Republic of \\ Korea \\ *leechodg@scnu.ac.kr
}

\begin{abstract}
The powder bed fusion method using a heat source for 3D printing can be applied to fabricate the geometrical shapes of some parts, and enables rapid melting and cooling. 3D EBM additive manufacturing can supply a near-net-shape or net-shape and precise parts better than micro scale casting and precision casting. Casting parts have residual stress in the matrix and their microstructure, which can affect the dynamic properties, but if they are heat-treated under the optimal conditions, the residual stress can be reduced to enhance the dynamic-mechanical properties of $3 \mathrm{D}$ printed parts. In this study, Ti-6Al-4V bulk bars were fabricated by EBM additive manufacturing, and the microstructures, residual stress, and various interior defects of the specimens were analyzed. The residual stress and surface tension were measured and calculated in different specimens heat-treated at $850 \sim 950{ }^{\circ} \mathrm{C}$. The relationship between the residual stress and surface tension was explained using the related equations and the influence on the high cycle fatigue properties was evaluated.
\end{abstract}

\section{Introduction}

3D additive manufacturing (AM) uses a powder or wire to fabricate geometrical shapes with strong heat sources. Among 3D AM, powder bed fusion (PBF) is a method that places the powder on the layer and scans the beam spot according to the shape coordinates. The electron beam melting (EBM) and electron beam additive manufacturing (EBAM) method are PBF processing methods. In particular, when powder is used to fabricate a shape, the additive manufactured products have some pores inside the parts [1]. Pores are a crucial detrimental factor for 3D EBM parts [2,3]. The AM method includes rapid heating and cooling processes [4]; therefore, 
considerable residual stress and pores remain inside the parts [5]. The 3D AM studies connected with the residual stress and fatigue crack initiation mechanism were insufficient. Surface energy generating micro crack [6] should be eliminated and reduced. Fatigue strength can be explained by relationships between residual stress and surface tension which be detrimental elements of the material. Nano-indenters, which can measure the nano-hardness, have been introduced to calculate the residual stress [7]. FRONTICS, Inc. [8] proposed an equation that evaluates the residual stress through the sum of tensile stress and compressive stress:

$$
\sigma_{r e s}^{x}+\sigma_{r e s}^{y}=\frac{3}{\Psi} \frac{\Delta L}{A_{c}},
$$

Where $\Delta \mathrm{L}\left(=\mathrm{L}_{1}-\mathrm{L}_{0}\right)$ is the difference in load $\left(\mathrm{L}_{0}\right.$ the measured maximum indentation load; $\mathrm{L}_{1}$ is the calculated maximum indentation load in the indentation depth curve); $\Psi$ is the constraining factor and $A_{c}$ is the actual contact area. W. Wang et al. [9] proposed an equation showing that the surface energy around a pore is related to pore radius and surface tension:

$$
\Lambda=\frac{\sigma_{1}^{2} R_{0}}{Y \gamma_{t}}
$$

The factor ' $\Lambda$ ' affects the pore morphology when an external stress is applied to the pore, and this value can change itself. According to the above equation, $\gamma_{t}$ (surface tension) can be resolved by a fixed factor, $\Lambda, \sigma$ (residual stress), $\mathrm{R}_{0}$ (pore radius), and $\mathrm{Y}$ (Elastic modulus).

In this study, the relationships between the residual stress, and surface tension according to various heat treatment conditions were analyzed and the changes in their values were measured in regions with and without pores inside the EBM Ti-6Al-4V specimens. The purpose of this research was to find out the optimum condition to decrease the residual stress and the degree of the residual stress by heat treatment. The relationship between the residual stress and surface tension was explained using the related equations. The high cycle fatigue properties as a function of the heat treatment conditions were evaluated and the correlation between their values and the residual stress were investigated.

\section{Material and experiments}

Ti-6Al-4V powder supplied by Advanced Powder and Coatings Inc., Canada was used in this study. The powder size was approximately $73 \mu \mathrm{m}$ and the AM samples were fabricated by an electron beam melting method that used an Arcam EBM-A2X device (Arcam AB, Molndal, Sweden). The geometry of the EBM samples was the shape of the bulk bar $(\Phi 12 \times 68 \mathrm{~mm})$ and was 
fabricated in the vertical direction. The Building conditions of the specimen were followed as accelerated voltage $60 \mathrm{kV}$, beam current $4 \mathrm{~mA}$, line offset $0.1 \mathrm{~mm}$, layer thickness $50 \mu \mathrm{m}$ and scan speed of $500 \mathrm{~mm} / \mathrm{s}$. Various heat treatments were carried out to compare the properties with the as-fabricated specimen: $850^{\circ} \mathrm{C} / 30 \mathrm{~min}, 900^{\circ} \mathrm{C} / 30 \mathrm{~min}, 950^{\circ} \mathrm{C} / 30 \mathrm{~min}$, and followed by air cooling. The residual stress was evaluated according to the heat treatment conditions.

The residual stress of EBM Ti-6Al-4V alloy specimens was measured using a Nanoindenter (CSM Instruments, NHT2). This method evaluates the nano hardness, which gives a loading force to the surface by the nano indenter tip and calculates the hardness. Some pores were present inside most specimens so the hardness was measured around the pore and inside the base metal without pores. This was carried out with a $50 \mathrm{mN}$ loading around pores larger than $50 \mu \mathrm{m}$ and at the positions $8 \mu \mathrm{m}$ and $32 \mu \mathrm{m}$ from the pore. The measured hardness was converted to the residual stress using Eq. (1). $\Psi$ was fixed to 0.5 , which is based on examples of license patents [8]:

$$
A_{c}=24.5\left(h_{c}^{t}\right)^{2}
$$

Where $A_{c}$ is the actual contact area measured by a nano indenter and $h_{c}{ }^{t}$ is the actual contact depth. The Berkovich type of indenter, which can affect the contact area, was used in this experiment.

The pore size of the heat-treated Ti-6Al-4V specimens was measured under different conditions. The actual contact area $\left(\mathrm{A}_{\mathrm{c}}\right)$ of each heat-treated specimen was calculated using the nano hardness and the factor ' $\Lambda$ ' was fixed to 0.2. The residual stress was calculated using Eq. (1) and the surface tension was finally calculated using Eq. (2). W. Wang reported that when the critical value was 0.27 to 0.38 , spherical pores can transform to elliptical types or grow crack tips [9]. On the other hand, no changes in pore shape were detected and the factor ' $\Lambda$ ' was fixed to 0.2 .

The high cycle fatigue strength of the EBM specimens was determined using a dynamic rotation bending fatigue tester (KDMT-240, KT $2015-1015$ ). The fatigue cycle was aimed at $10^{7}$ cycles with a load of more than $400 \mathrm{MPa}$.

\section{Results and discussion}

\subsection{Residual stress and surface tension}

Nano indentation measurements of the surface of EBM Ti-6Al-4V specimen were carried out around the pore and matrix. Fig. 1(a) shows the typical load-depth curve involving the load 
difference $(\Delta \mathrm{L})$ and actual contact depth $\left(\mathrm{h}_{\mathrm{c}}{ }^{\mathrm{t}}\right)$ values. The average value of $\mathrm{h}_{\mathrm{c}}{ }^{\mathrm{t}}$ was approximately $650 \pm 50 \mathrm{~nm}$. Fig. 1(b)-(c) presents the nano indentation marks at the near region around the pore, more than $50 \mu \mathrm{m}$ in size, and inside the matrix.

(a)

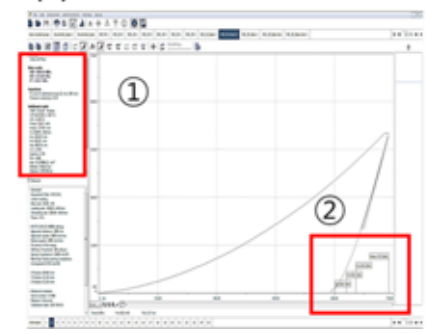

(b)

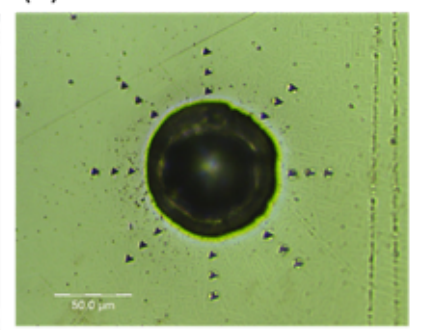

(c)

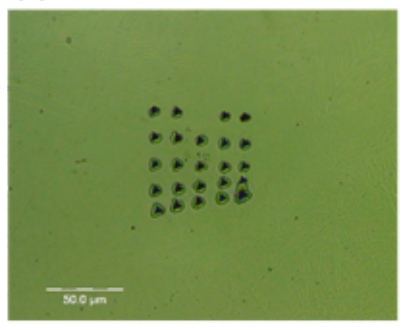

Fig. 1. Nano indentation measurements of EBM 3D-printed Ti-6Al-4V specimens; (a) load-depth curve by the nano indentation, (b) around the pore over $50 \mu \mathrm{m}$ and (c) in the matrix without pores.

Table 1. Distribution of the residual stress measured according to the position from the pore at each heat treatment conditions.

\begin{tabular}{|c|c|c|c|}
\hline $\begin{array}{c}\text { Position from the pore } \\
\left(\text { Residual stress: } \sigma_{\text {res }}^{x}+\sigma_{\text {res }}^{y}\right)\end{array}$ & $\begin{array}{c}\sim 8 \mu \mathrm{m} \text { point } \\
(\mathrm{MPa})\end{array}$ & $\begin{array}{c}\sim 32 \mu \mathrm{m} \text { point } \\
(\mathrm{MPa})\end{array}$ & Matrix \\
\hline As-fabricated & 28.8 & 15.985 & 24.171 \\
\hline $850^{\circ} \mathrm{C} / 30 \mathrm{~min} / \mathrm{AC}$ & 27.1 & 19.43 & 16.785 \\
\hline $900^{\circ} \mathrm{C} / 30 \mathrm{~min} / \mathrm{AC}$ & 19.4 & 17.5 & 17.4 \\
\hline $950^{\circ} \mathrm{C} / 30 \mathrm{~min} / \mathrm{AC}$ & 23.858 & 24.882 & 21.277 \\
\hline
\end{tabular}

From these curves, the residual stress can be calculated using Eq. (1) for the as-fabricated and heat-treated samples. Table 1 lists the change in residual stress according to the position from the pores. The residual stress decreased with increasing distance from the pore and the residual stress around the pore was higher than that inside the matrix. At $900^{\circ} \mathrm{C}$, the residual stress changed 
from $19.4 \mathrm{MPa}$ to $17.5 \mathrm{MPa}$ and $17.4 \mathrm{MPa}$, according to the position from the $8 \mu \mathrm{m}$ point to the 32 $\mu \mathrm{m}$ point inside the matrix, respectively. These values were lower than those of the as-fabricated sample, which means a decrease in residual stress by post heat treatment. This can have a positive influence on the dynamic properties of the 3D additive manufactured parts.

The surface tension was calculated using Eq. (2), which was transformed to Eq. (4):

$$
\Upsilon_{t}=\frac{\sigma_{1}^{2} R_{0}}{\Lambda \mathrm{Y}}
$$

Where $\gamma_{t}$ is the surface tension and factor $\Lambda$ was fixed to 0.2 , as mentioned above. The measured pore radius was inserted into $\mathrm{R}_{0}$. The overall tendency of the surface tension by the different heat treat conditions was evaluated. The surface tension was calculated and compared with the residual stresses under each post heat treatment condition, as shown in Fig. 2. The pore sizes were measured from more than 46 pores to increase the reliability of the surface tension measurements under each condition.

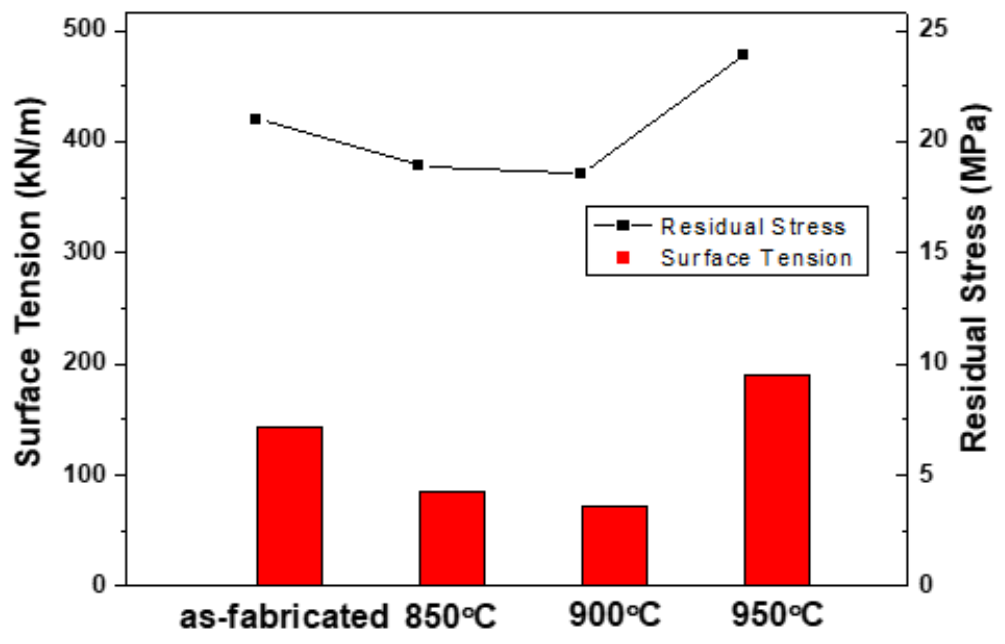

Fig. 2. Variation of surface tension and residual stress at several heat treatment conditions for 3D EBM Ti6Al-4V alloy.

The surface tension was similar to the trend of the residual stresses. Surface tension decreased in the order of the as-fabricated, $850^{\circ} \mathrm{C}$, and $900^{\circ} \mathrm{C}$. In the case of the $950^{\circ} \mathrm{C}$ condition, a high surface tension was calculated because there were large pores and high residual stress due to the rapid cooling rate. As the surface tension increases, the specimen has high surface energy [10] 
and becomes unstable. As a result, the dynamic properties of the specimen become weaker, resulting in lower surface tension. From Fig. 2, the optimal heat treatment conditions were $850^{\circ} \mathrm{C} \sim 900^{\circ} \mathrm{C}, 30 \mathrm{~min}$, and air cooling, and the dynamic properties would be enhanced by post heat treatment under these conditions.

\subsection{Fatigue properties}

Fig. 3 shows the fatigue results of the as-fabricated specimen and the specimens heat-treated under the three conditions. As the trend line of the fatigue stress moves in the right and upward direction, the dynamic fatigue properties generally increase. The sample heat-treated at $850^{\circ} \mathrm{C}$ had better fatigue properties than those at $900^{\circ} \mathrm{C} \sim 950^{\circ} \mathrm{C}$.

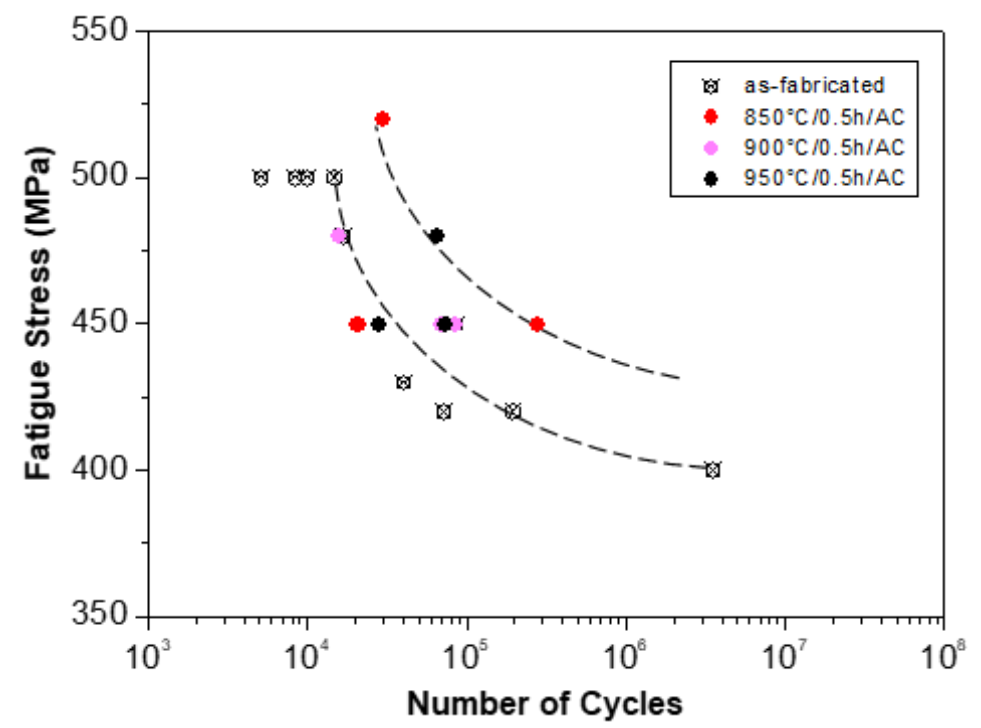

Fig. 3. High cycle fatigue S-N curves of EBM Ti-6Al-4V specimens at several heat treatment conditions

The fatigue limit of the 3D-printed EBM Ti-6Al-4V is generally $~ 400 \mathrm{MPa}$, so fatigue testing was carried out over $400 \mathrm{MPa}$. As shown in Fig. 3 , the $850^{\circ} \mathrm{C}$ specimen showed a larger number of cycles than the as-fabricated sample under a higher load (520MPa). At constant failure cycles, the fatigue stress at $850^{\circ} \mathrm{C}$ was higher $(450 \mathrm{MPa})$ than that of the as-fabricated sample (420MPa). The cycles for fatigue failure at $850^{\circ} \mathrm{C}$ was $3 \times 10^{5}$ cycles under a $450 \mathrm{MPa}$ load and the cycles under the $900^{\circ} \mathrm{C}$ condition was $1 \times 10^{5}$ cycles under the same load. 3D printed parts fabricated by the EBM method had various crack initiation sites, e.g., surface defects, and internal defects, such as gas porosity, lack of fusion, and $\alpha$-phase facet cluster [11-13]. No significant defects except for porosity were observed at $850^{\circ} \mathrm{C}$ and the high cycle fatigue property was higher than that under 
any other condition. The residual stress and surface tension at $900^{\circ} \mathrm{C}$ were superior to those at $850^{\circ} \mathrm{C}$. This is because of the pore size and number inside the specimen; specifically, there were many large pores, approximately $53 \mu \mathrm{m} \sim 94 \mu \mathrm{m}$ in size at $900{ }^{\circ} \mathrm{C}$, and small size pores, approximately $35 \mu \mathrm{m} \sim 51 \mu \mathrm{m}$ in size, at $850^{\circ} \mathrm{C}$. The pore size and distribution at various post heat treatments were studied in the other report [14]. The dynamic high cycle fatigue property is affected more strongly by large pores than the residual stress and surface tension. Therefore, the specimen at $850^{\circ} \mathrm{C}$ showed superior high cycle fatigue property than the as-fabricated sample and those under the other heat treatment conditions.

\section{Conclusion}

3D-printed Ti-6Al-4V parts were fabricated by EBM additive manufacturing and exhibited residual stress and various interior defects, which could degrade the dynamic-mechanical properties. Pore occurrence was not avoided during the 3D printing process, which could introduce surface tension and residual stress around the pore. To decrease the influence, post heat treatments were carried out under the three conditions. As a result, the heat-treated samples had lower residual stress and surface tension than the as-fabricated sample at $850 \sim 900^{\circ} \mathrm{C}$. The fatigue limit of the sample heat-treated at $850^{\circ} \mathrm{C}$ was estimated to be $20 \sim 30 \mathrm{MPa}$ higher than the asfabricated sample. Appropriate post heat treatment could have positive effects on enhancing the high cycle fatigue of $3 \mathrm{D}$ additive manufacturing parts.

\section{Acknowledgments}

This study was supported by the Technology Innovation Program (No.10053101, No.10063269 and No.P0002019) funded by the Ministry of Trade, Industry \& Energy (MOTIE) and the Korea Evaluation Institute of Industrial Technology (KEIT). The authors wish to thank to Mr. Sang-Yeob Lim (Korea Atomic Energy Research Institute) and Dr. Byeongsoo Lee (Korea Institute of Industrial Technology) for their support.

\section{References}

[1] S. Biamino, A. Penna, U. Ackelid, S. Sabbadini, O. Tassa, P. Fino, M. Pavese, P. Gennaro, C. Badini, Intermetallics 19 (2011) 776-781.

[2] H. Gong, K. Rafi, H. Gu, G.D. Janaki Ram, T. Starr, B. Stucker, Mater. Des. 86 (2015) 545554.

[3] T. Sercombe, N. Jones, R. Day, A. Kop, Rapid Prototyp. J. 14 (2008) 300-304. 
[4] L.E. Murr, Metallurgy of additive manufacturing: Examples from electron beam melting, Additive Manufacturing 5 (2015) 40-53.

[5] X. Wang, K. Chou, Proc. International solid freeform fabrication symposium (2015) 14631474.

[6] H. Matsushita and K. Onoue, Journal of Advanced Concrete Technology 4 (2006) 409-421.

[7] C. Jacq, G. Lormand, D. Nelias, D. Girodin, A. Vincent, Mater. Sci. Eng., A 342 (2003) 311319.

[8] M.J. Choi, Y.C. Kim, K.H. Kim, WO Patent 2014119817 (2014).

[9] W. Wang, Z. Suo, J. Mech. Phys. Solids 45 (1997) 709-729.

[10] S.W. IP, J.M Toguri, J. Mater. Sci. 29 (1994) 688-692.

[11] Y.S. Choi, C.L. Kim, G.H. Kim, B.S. Lee, C.W. Lee, D-G. Lee, Appl. Mech. Mater. 873 (2017) 54-59.

[12] V. Chastand, P. Quaegebeur, W. Maia, E. Charkaluk, Mater. Charact. 143 (2018) 76-81.

[13] J. Gunther, D. Krewerth, T. Lippmann, S. Leuders, T. Troster, A. Weidner, H. Biermann, T. Niendorf, Int. J. Fatigue 94 (2017) 236-245.

[14] Y.S. Choi, J.H. Jang, G.H. Kim, C.W. Lee, H.J. Kim and D-G. Lee, J. Korean Powder Metall. Inst., 25 (2018) 340-345. 